\title{
cámara de curado, de temperatura y humedad constante
}

(A constant temperature and humidity curing cabinet)

B. P. HUGHES

De: «Magazine of Concrete Research», vol. 8, núm. 24, noviembre 1956, pág. 161

\section{S I N O P S I S}

Se describe una cámara de curado, construida en el Civil Engineerlng Department of the University of Birmingham, como preparación para un programa de fnvestigación sobre hormigones. Sa costo es, relativamente, redueido. Su empleo es muy adecnado en todos aquellos casos en que no es posible conseguir un control preciso de la temperatura de todo el laboratorio.

\section{INTRODUCCION}

Las características exigidas para la cámara de curado eran las de una variación máxima de temperatura de $\pm 1^{\circ} \mathrm{F}\left( \pm 1,8^{\circ} \mathrm{C}\right)$ en el depósito de agua, y de $\pm 2^{\circ} \mathrm{F}\left( \pm 3,6^{\circ} \mathrm{C}\right)$ y una humedad relativa superior a $90 \%$ para la sección de curado en aire húmedo.

Estas condiciones se han logrado, sobradamente, con la presente cámara de curado, que se halla en funcionamiento desce hace dos años. El costo total de los materiales y de la instalación necesaria para la cámara fué inferior a $60 \mathrm{f}$. Este valor tan reducido se consiguió ellminando la necesidad de un control separado de temperatura para cada sección de la cámara y de una instalación de refrigeración.

\section{CARACTERISTICAS FUNDAMENTALES}

La cámara de curado consiste, fundamentalmente, en dos depósitos de agua, galvanizados, colocados uno junto al otro y rodeados por una estructura aislante. El depósito de agua a temperatura constante mide 5 pies $\times 3$ pies $\times 2$ pies 8 pulgadas $(1,52 \times 0,91 \times 0,80 \mathrm{~m})$, mientras que el otro tanque para curado en aire húmedo a temperatura constante mide 3 pies $\times 2$ pies 4 pulgadas $\times 2$ pies $(0,91 \times 0,70 \times 0,60 \mathrm{~m})$.

El aislamiento se ha conseguido mediante una capa, de 1 pulgada $(2,54 \mathrm{~cm})$ de espesor, de lana de roca, dispuesta entre los depósitos, y un revestimiento de planchas, fijadas a la estructura de madera. La tapa y la puerta están revestidas interiormente por láminas de zinc. Se consiguió un exceiente contacto térmico entre los dos tanques, mediante virutas metallcas dispuestas entre ambos.

El tanque para curado en afre puede contener 32 molơes cúbicos de 4 pulgadas (10,16 $\mathrm{cm}$ ), mientras que el depósito de agua puede albergar ocho grupos de quince cubos cada uno. 


\section{FUNCIONAMIENTO}

El agua entra en el depósito de temperatura constante a través de un tubo que se extiende por la parte inferior del tanque, recorriéndolo tres veces longitudinalmente. El trayecto central presenta un cierto número de pequeños oriflcios, distribuídos a ambos lados del mismo. De este modo se consigue una distribución uniforme del agua y un cierto precalentamiento de la misma. El gasto se controla mediante una válvula de bola y puede, además, regularse por un grifo situado en el exterior.

La temperatura del agua se mantiene a $63^{\circ} \mathbf{F}\left(17,2^{\circ} \mathrm{C}\right)$, mediante un control electrónico, que asegura una variación máxima de $\pm 1 / 2^{\circ} \mathrm{F}\left( \pm 0,9^{\circ} \mathrm{C}\right)$. Este control actúa, a través de un relé sobre un cable de calefacción, de 100 pies de longitud $(30,48 \mathrm{~m})$, de $11 / 2 \mathrm{~kW}$. Este cable se encuentra colgado bajo el tubo de entrada de agua y justamente encima del fondo del depósito, sobre el cual se halla distribuido uniformemente con objeto de asegurar una calefacción uniforme.

Se pensó, en un principio, que a pesar de las corrientes uniformes de convección, creadas mediante esta disposición, no se podría conseguir una temperatura constante en todo el tanque. Por esta razón se instaló un dispositivo de agitación; constaba de unas paletas montadas sobre dos ejes, movidos por un motor eléctrico. Sin embargo, se comprobó que estos agitadores eran totalmente innecesarios, pues que, aun sin ellos, la variación máxima de temperatura era de $\pm 1 / 2^{\circ} \mathrm{F}\left( \pm 0,9^{\circ} \mathrm{C}\right)$, aproximadamente.

Las probetas cúbicas se disponen sobre una rejilla metálica, formada por varillas de $3 / 8$ pulgadas $(0,95 \mathrm{~cm})$, situadas a distancias de 3 pulgadas $(7,63 \mathrm{~cm})$; esta rejilla se encuentra encima del tubo de entrada del agua y del cable de calefacción. Las probetas pueden colocarse adecuadamente, en forma alternada.

El agua fluye constantemente, saliendo por el rebosadero. De este modo se consigue que el depósito permanezca limpio en todo momento, y además se elimina la necesidad de disponer una instalación de refrigeración. Se supone, desde luego, que el agua que entra en el depósito se halla a una temperatura inferior a la que se requiere en la cámara. En Inglaterra se ha aceptado, de forma general, como temperatura normal de curado, la de $64^{\circ} \mathrm{F}\left(17,7^{\circ} \mathrm{C}\right)$, de modo que sí el agua se toma de la conducción general, no se tropezará con diflcultades.

Durante el invierno, el gasto de agua que penetra en el depósito se reduce al minimo necesario para que aquél permanezca constantemente limpio. En verano es preciso elevarlo ligeramente, con objeto de eliminar el calor que pudiera absorberse del laboratorio. El excelente aislamiento asegura que esta absorción de calor es prácticamente despreciable, de modo que, aun en el tiempo más caluroso, el gasto de agua puede ser pequeño.

El nivel del agua puede regularse variando el peso del flotador de la válvula indicada, o modiflcando la altura del conducto de salida.

El tubo de entrada penetra en el depósito de curado en atmósfera húmeda a unás 3 pulgadas $(7,62 \mathrm{~cm})$ por debajo del nivel del agua en el depósito principal. Este tubo atraviesa tres lados del depósito pequeño; en todo su recorrido presenta una serie de pequeños orificios, practicados a distancia de 2 pulgadas $(5,08 \mathrm{~cm}$ ). Una pendiente adecuada del tubo hace posible que el gasto a través de cada orificlo sea el mismo. Este flujo puede regularse modificando el nivel del agua en el depósito principal. Debajo de cada chorro se encuentran dispuestos filtros, que se hallan continuamente saturados. El nivel del agua en este depósito se mantiene a una altura constante de una puigada $(2,54 \mathrm{~cm})$, gracias a otro rebosadero.

En este depósito se hallan dispuestas unas rejillas de madera. Cuando se cierra la puerta, la humedad relativa es de $95 \%$, y la variación máxima de temperatura de $\pm 1^{\circ} \mathbf{F}\left( \pm 1,8^{\circ} \mathbf{C}\right)$. 